\title{
Nasal Nitric Oxide in Healthy Adults - Reference Values and Affecting Factors
}

\author{
M. ANTOSOVA ${ }^{1}$, D. MOKRA ${ }^{1,2}$, I. TONHAJZEROVA ${ }^{1,2}$, P. MIKOLKA $^{1}$, P. KOSUTOVA ${ }^{2}$, \\ M. MESTANIK ${ }^{1,2}$, L. PEPUCHA ${ }^{3}$, J. PLEVKOVA ${ }^{4}$, T. BUDAY ${ }^{4}$, V. CALKOVSKY ${ }^{5}$, \\ A. BENCOVA ${ }^{6}$
}

${ }^{1}$ Biomedical Center Martin, Jessenius Faculty of Medicine in Martin, Comenius University in Bratislava, Martin, Slovakia, ${ }^{2}$ Department of Physiology, Jessenius Faculty of Medicine, Comenius University in Bratislava, Martin, Slovakia, ${ }^{3}$ Research Centre, University of Zilina, Zilina, Slovakia, ${ }^{4}$ Department of Pathophysiology, Jessenius Faculty of Medicine, Comenius University in Bratislava, Martin, Slovakia, ${ }^{5}$ Clinic of Otorhinolaryngology and Head and Neck Surgery, Jessenius Faculty of Medicine in Martin and University Hospital Martin, Comenius University in Bratislava, Martin, Slovakia, ${ }^{6}$ Clinic of Pneumology and Phthisiology, Jessenius Faculty of Medicine and University Hospital Martin, Comenius University in Bratislava, Martin, Slovakia

Received April 7, 2017

Accepted April 30, 2017

\section{Summary}

Nitric oxide (NO) is an important endogenous mediator with significant role in the respiratory system. Many endogenous and exogenous factors influence the synthesis of $\mathrm{NO}$ and its level is significantly changed during the inflammation. Analysis of nasal nitric oxide (nNO) is not validated so far as the diagnostic method. There is a lack of reference values with possible identification of factors modulating the nNO levels. In healthy adult volunteers $(n=141)$ we studied nasal NO values by NIOX MINO ${ }^{\circ}$ (Aerocrine, Sweden) according to the recommendations of the ATS \& ERS. Gender, age, height, body weight, waist-to-hip ratio, FEV1/FVC, PEF and numbers of leukocytes, eosinophils, basophils and monocytes were studied as potential variables influencing the levels of nNO. The complexity of the results allowed us to create a homogenous group for nasal NO monitoring and these data can be used further as the reference data for given variables. Because of significant correlation between $\mathrm{nNO}$ and exhaled NO, our results support the "one airway - one disease" concept. Reference values of nasal NO and emphasis of the individual parameters of tested young healthy population may serve as a starting point in the non-invasive monitoring of the upper airway inflammation.

\section{Key words}

Nasal nitric oxide $\bullet$ Reference values $\bullet$ Correlation

\section{Corresponding author}

M. Antosova, Biomedical Center Martin, Division of Respirology Jessenius Faculty of Medicine in Martin, Comenius University in Bratislava, Malá Hora 4C, 03601 Martin, Slovakia. E-mail: antosova@jfmed.uniba.sk

\section{Introduction}

Nitric oxide (NO) plays substantial role in the airways. In addition to regulating bronchomotor tone it participates in many physiological processes, including regulation of blood flow and immunomodulation (Kopincova et al. 2008). NO is produced by three types of NO synthase - endothelial (eNOS), neuronal (nNOS) and inductive (iNOS). While the first two isoforms are active mainly in physiological conditions, activity of iNOS increases especially during pathological processes, e.g. inflammation (Antosova et al. 2015). The detection of extremely low concentrations of NO in exhaled air (Gustafsson et al. 1991) and results of significant correlation between exhaled NO and eosinophilic inflammation in the airways (Jatakanon et al. 1998) increased the interest in NO detection methods in subjects with respiratory diseases.

Method of exhaled NO (FeNO) measurement reached the clinical practice relatively quickly and first 
recommendations for standardized FeNO measurement were published by ATS \& ERS in 2005. Measurement of FeNO became essential diagnostic tool in pulmonology as non-invasive alternative to invasive and time-consuming methods for diagnosis and control of asthma (Balbi et al. 2007).

$\mathrm{NO}$ is an important mediator also in the upper airways, mainly in the nose and sinuses. Nasal NO (nNO) was first detected in 1993 by Alving et al. who found out that most of exhaled NO originates in the nose. Its main function in control of ciliary movement and defense processes (Struben et al. 2006) implies the utilization of this method in diagnostics of e.g. primary ciliary dyskinesia or inflammation in the upper airways (Lee et al. 2012).

Nevertheless, detection of $\mathrm{nNO}$ is not a routine diagnostic method yet, with exception of ciliary disorders (Leigh et al. 2013). The reason is ambiguous approach to detection technology, the difference in devices used for detection or lack of information on factors affecting $\mathrm{nNO}$ (Jorrisen et al. 2001). There is high inter-individual variability amongst healthy population, variation over time and lack of universal standardization of testing procedure. nNO levels recorded by different study groups vary considerably even amongst equivalent patient populations (Scadding and Scadding 2009). ERS made an attempt to standardize nNO detection and identify the reference values (Kharitonov et al. 1997); however, the doubts and inconsistencies still remain. These are caused mainly by poor description of variety of biological factors influencing NO levels (e.g. gender, age, menstrual cycle, BMI). The aim of our study was to identify the reference values of nNO in population of young healthy adults and to clarify the effect of selected variables on nNO levels.

\section{Methods}

The study protocol was approved by the Ethical Committee of JFM CU in Martin. One hundred forty-one healthy volunteers were recruited for the study (47 men and 94 women, mean age 25 years). The basic exclusion criteria were: age over 50 years and less than 18 years, smoking, allergies, chronic diseases, obesity, acute respiratory infection and presence of symptoms such as cough, dyspnea, runny nose and sneezing. All volunteers were examined by otorhinolaryngologist. In the medical history, no health problems related to the upper and lower respiratory system were reported. At medical investigation, $66 \%$ of healthy volunteers had slight deviation of the nasal septum with no signs of nasal obstruction. This number is in accordance with clinical practice. All other findings in the ENT organs were physiological.

Prior to recruitment, each subject was informed about the study protocol and methods and signed informed consent. The study consisted of interrelated investigations carried out in three consecutive days: Day 1 - basic anthropometric measurements, venous blood sampling and lung function tests, Day 2 measurement of FeNO, and Day 3 - measurement of nNO.

Measurement of FeNO and nNO was performed separately on the day 2 and 3 to avoid any influence of lung function testing and stress caused by blood sampling. Subjects were tested early in the morning and measurement strictly followed ATS \& ERS guidelines.

\section{Anthropometric measurements}

Basic anthropometric parameters such as body height and weight, waist-hip ratio (WHR) and body mass index (BMI) were obtained. Percentage of body fat was assessed by standardized automatic device OMRON BF306.

\section{Lung function tests}

Lung function tests were performed by Spiro Scout (Ganshorn). After 3-4 normal breathing cycles, volunteers performed a manoeuver of forced expiration. Forced expiratory volume in $1 \mathrm{~s}$ (FEV1), FEV1/FVC ratio and peak expiratory flow (PEF) were automatically calculated. Calculation of Miller score was used to identify physiological findings without restriction, obstruction or combined ventilatory disorder.

\section{Hematologic examination}

A sample of $5 \mathrm{ml}$ of venous blood was drawn in the EDTA test tubes. Blood samples were analyzed by hematologic analyzer (Mindray BC-5500) and total white blood cells (WBC) count, differential WBC count, absolute and relative count of neutrophils (NEU), lymphocytes (LYM), monocytes (MON), eosinophils (EOS) and basophils (BAS) were evaluated.

All subjects with abnormal lung function and/or hematologic parameters were excluded from the study.

\section{Measurement of FeNO and $n N O$}

Measurements of FeNO and nNO were performed by analyzer NIOX MINO $^{\circledR}$ (Aerocrine, Sweden) according to ATS \& ERS guidelines. The test was carried out in sitting position after $15 \mathrm{~min}$ of rest after education of the subjects. For FeNO, subjects inhaled air without $\mathrm{NO}(\mathrm{NO}<5$ parts per billion, $\mathrm{ppb})$ via 
mouthpiece with filter until total lung capacity (TLC) was reached. Inhalation was followed by exhalation via mouthpiece lasting up to $10 \mathrm{~s}$ with at least $6 \mathrm{~s}$ plateau of NO values detected automatically by the device. Exhalation was maintained at the flow $50 \mathrm{ml} . \mathrm{s}^{-1}$. Values of FeNO were expressed in ppb, which is an equivalent to nl. $1^{-1}$ (ATS and ERS 2005).

Detection of nNO was performed using research application of NIOX MINO. nNO was measured in each nostril ( $\mathrm{RnNO}$ - right nostril, LnNO - left nostril) during passive aspiration of air via special ergonomic olive (filter) at the flow $5 \mathrm{ml} . \mathrm{s}^{-1}$, with tidal breathing technique with velum closure. Values of nNO were expressed in ppb.

\section{Statistical analysis}

Values of FeNO, nNO and differences between left and right nostril were analyzed by Student's t-test. Value of $\mathrm{p}<0.05$ was considered statistically significant. Correlation between selected parameters and FeNO and nNO respectively, were calculated by Pearson correlation analysis. Results, or correlation intensity, were evaluated in accordance to recommendation of Evans (1996), which are used for correlation intensity evaluation. Absolute value of correlation coefficient $\mathrm{r}=0.00-0.19$ indicates "very weak" correlation, $\mathrm{r}=0.20-0.39$ indicates "weak"; $\mathrm{r}=0.40-0.59$ "moderate", $\mathrm{r}=0.60-0.79$ "strong" and $\mathrm{r}=0.80-1.00$ indicates "very strong" correlation of variables.

\section{Results}

\section{Anthropometric measurements}

Average height of study population was $171.6 \pm 9.9 \mathrm{~cm}(181.3 \pm 7.2 \mathrm{~cm}$ for men; $166.9 \pm 7.3 \mathrm{~cm}$ for women) and average body weight was $66.7 \pm 13.2 \mathrm{~kg}$ (79.8 $\pm 10.4 \mathrm{~kg}$ for men; $60.0 \pm 8.7 \mathrm{~kg}$ for women). BMI was calculated based on basic anthropometric parameters, average value of which was $22.5 \pm 3.2$ for study population $-24.4 \pm 3.3$ for men and $21.5 \pm 2.7$ for women. This information was supplemented by WHR index with average value 0.8 in study population ( 0.9 for men; 0.7 for women) and by body fat percentage - average value for study population was $20.3 \%$ (15.7\% for men; $22.6 \%$ for women). Anthropometric measurements show that volunteers have had "optimal weight" and "optimal" body fat distribution. Significant differences between men and women in all measured parameters $(p<0.0001)$ were expected as a result of different composition of male and female body (Tables 1-3).

Table 1. Correlation analysis between NO measured in left nostril (LnNO) and right nostril (RnNO) and selected parameters in entire group of healthy volunteers.

\begin{tabular}{|c|c|c|c|c|c|}
\hline All Respondents & $\operatorname{mean} \pm \mathrm{SD}$ & r(RnNO) & $\mathbf{p}$ & r(LnNO) & $\mathbf{p}$ \\
\hline Number of respondents & 141 & 141 & & 141 & \\
\hline Age (year) & $25.6 \pm 9.8$ & 0.3 & 0.001204 & 0.3 & 0.001204 \\
\hline Height $(\mathrm{cm})$ & $171.6 \pm 9.9$ & -0.05 & 0 & -0.06 & 0 \\
\hline Body weight (kg) & $66.7 \pm 13.2$ & -0.2 & 0.024031 & -0.2 & 0.024031 \\
\hline$B M I\left(w / h^{2}\right)$ & $22.5 \pm 3.2$ & 0.4 & $<0.00001$ & 0.4 & $<0.00001$ \\
\hline$F E V_{1} / F V C(\%)$ & $83.5 \pm 13.0$ & -0.1 & 0 & 0.02 & 0 \\
\hline $\operatorname{PEF}\left(l . s^{-1}\right)$ & $6.6 \pm 2.0$ & 0.01 & 0 & 0.07 & 0 \\
\hline$W B C\left(\right.$ count $\left.\times 10^{9} \cdot l^{-1}\right)$ & $7.6 \pm 1.8$ & -0.2 & 0.014747 & -0.3 & 0.002276 \\
\hline $\operatorname{EOS}\left(\right.$ count $\left.\times 10^{9} \cdot l^{-1}\right)$ & $3.0 \pm 1.8$ & 0.1 & 0 & 0.2 & 0.027225 \\
\hline$B A S\left(\right.$ count $\left.\times 10^{9} . l^{-1}\right)$ & $0.4 \pm 0.2$ & -0.2 & 0.021851 & $-0,1$ & 0 \\
\hline $\operatorname{MON}\left(\right.$ count $\left.\times 10^{9} \cdot l^{-1}\right)$ & $7.8 \pm 2.0$ & 0.1 & 0 & 0.2 & 0.045141 \\
\hline$N E U\left(\right.$ count $\left.\times 10^{9} \cdot l^{-1}\right)$ & $51.2 \pm 8.2$ & -0.2 & 0.020494 & -0.1 & 0 \\
\hline$L Y M\left(\right.$ count $\left.\times 10^{9} \cdot l^{-1}\right)$ & $37.1 \pm 8.0$ & 0.2 & 0.020494 & 0.1 & 0 \\
\hline FeNO50 (ppb) & $21.6 \pm 14.7$ & 0.4 & $<0.00001$ & 0.4 & $<0.00001$ \\
\hline$R n N O(p p b)$ & $379.6 \pm 170.4$ & & & & \\
\hline $\operatorname{LnNO}(p p b)$ & $401.6 \pm 207.8$ & & & & \\
\hline
\end{tabular}

BMI - body mass index, $\mathrm{w}$ - weight, $\mathrm{h}$ - height, $\mathrm{FEV}_{1}$ - forced expiratory volume in $1 \mathrm{~s}, \mathrm{FVC}$ - forced vital capacity, PEF - peak expiratory flow, WBC - white blood cells count, NEU - neutrophils, LYM - lymphocytes, MON - monocytes, EOS - eosinophils, BAS - basophils, I - liter, s - second, ppb - parts per billion, SD - standard deviation, $r$ - Pearson correlation coefficient, $\mathrm{p}$ - significance. 
Table 2. Correlation analysis between NO measured in left nostril ( $\mathrm{LnNO}$ ) and right nostril (RnNO) and selected parameters in women.

\begin{tabular}{|c|c|c|c|c|c|}
\hline WOMEN & $\operatorname{mean} \pm \mathrm{SD}$ & r (RnNO) & $\mathbf{p}$ & r (LnNO) & $\mathbf{p}$ \\
\hline Number of respondents & 94 & 94 & & 94 & - \\
\hline Age (year) & $25.8 \pm 10.2$ & 0.3 & 0.002894 & 0.4 & 0.000396 \\
\hline Height (cm) & $166.9 \pm 7.3$ & -0.02 & 0 & 0.02 & 0 \\
\hline Body weight (kg) & $60.0 \pm 8.7$ & 0.5 & $<0.00001$ & 0.6 & $<0.00001$ \\
\hline$B M I\left(w / h^{2}\right)$ & $21.5 \pm 2.7$ & 0.6 & $<0.00001$ & 0.7 & $<0.00001$ \\
\hline$F E V_{l} / F V C(\%)$ & $86.3 \pm 13.9$ & -0.1 & 0 & -0.13 & 0 \\
\hline $\operatorname{PEF}\left(l . s^{-1}\right)$ & $5.9 \pm 1.7$ & -0.09 & 0 & 0.06 & 0 \\
\hline$W B C\left(\right.$ count $\left.\times 10^{9} . l^{-1}\right)$ & $7.0 \pm 1.9$ & -0.2 & 0 & -0.2 & 0.04425 \\
\hline $\operatorname{EOS}\left(\operatorname{count} \times 10^{9} \cdot l^{-1}\right)$ & $2.9 \pm 1.6$ & 0.1 & 0 & 0.2 & 0 \\
\hline$B A S\left(\right.$ count $\left.\times 10^{9} . l^{-1}\right)$ & $0.4 \pm 0.2$ & -0.4 & 0.000429 & -0.2 & 0.02261 \\
\hline $\operatorname{MON}\left(\right.$ count $\left.\times 10^{9} . l^{-1}\right)$ & $7.7 \pm 2.0$ & 0.06 & 0 & 0.1 & 0 \\
\hline$N E U\left(\operatorname{count} \times 10^{9} \cdot l^{-1}\right)$ & $37.0 \pm 9.0$ & -0.12 & 0 & -0.02 & 0 \\
\hline$L Y M\left(\right.$ count $\left.\times 10^{9} \cdot l^{-1}\right)$ & $51.5 \pm 8.8$ & 0.09 & 0 & -0.04 & 0 \\
\hline FeNO5O (ppb) & $18.0 \pm 12.8$ & 0.6 & $<0.00001$ & 0.6 & $<0.00001$ \\
\hline RnNO (ppb) & $371.0 \pm 180.8$ & & & & \\
\hline $\operatorname{LnNO}(p p b)$ & $401.0 \pm 230.7$ & & & & \\
\hline
\end{tabular}

BMI - body mass index, $\mathrm{w}$ - weight, $\mathrm{h}$ - height, FEV1 - forced expiratory volume in $1 \mathrm{~s}, \mathrm{FVC}$ - forced vital capacity, PEF - peak expiratory flow, WBC - white blood cells count, NEU - neutrophils, LYM - lymphocytes, MON - monocytes, EOS - eosinophils, BAS - basophils, I - liter, s - second, ppb - parts per billion, SD - standard deviation, $r$ - Pearson correlation coefficient, $\mathrm{p}$ - significance.

Table 3. Correlation analysis between NO measured in left nostril (LnNO) and right nostril (RnNO) and selected parameters in men.

\begin{tabular}{|c|c|c|c|c|c|}
\hline MEN & Mean \pm SD & r (RnNO) & $\mathbf{p}$ & r (LnNO) & $\mathbf{p}$ \\
\hline Number of respondents & 47 & 47 & & 47 & \\
\hline Age (year) & $25.3 \pm 8.9$ & 0.2 & 0 & 0 & 0 \\
\hline Height $(\mathrm{cm})$ & $181.3 \pm 7.2$ & -0.4 & 0.004523 & -0.4 & 0.014941 \\
\hline Body weight (kg) & $79.8 \pm 10.4$ & -0.1 & 0 & -0.1 & 0 \\
\hline$B M I\left(w / h^{2}\right)$ & $24.4 \pm 3.3$ & 0.2 & 0 & 0.1 & 0 \\
\hline$F E V_{l} / F V C(\%)$ & $80.9 \pm 10.8$ & 0.1 & $\mathbf{0}$ & 0.3 & 0.018262 \\
\hline $\operatorname{PEF}\left(l . s^{-1}\right)$ & $7.9 \pm 2.1$ & 0.1 & 0 & 0.1 & 0 \\
\hline WBC $\left(\right.$ count $\left.\times 10^{9} \cdot l^{-1}\right)$ & $7.1 \pm 1.5$ & -0.4 & 0.001868 & -0.5 & 0.000368 \\
\hline $\operatorname{EOS}\left(\operatorname{count} \times 10^{9} . l^{-1}\right)$ & $3.3 \pm 2.3$ & 0.3 & 0 & 0.3 & 0 \\
\hline BAS $\left(\right.$ count $\left.\times 10^{9} \cdot l^{-1}\right)$ & $0.4 \pm 0.2$ & 0.3 & 0 & 0.3 & 0 \\
\hline $\operatorname{MON}\left(\operatorname{count} \times 10^{9} \cdot l^{-1}\right)$ & $7.9 \pm 1.9$ & 0.3 & 0 & 0.3 & 0.025815 \\
\hline$N E U\left(\right.$ count $\left.\times 10^{9} . l^{-1}\right)$ & $50.7 \pm 6.4$ & -0.4 & 0.002978 & -0.5 & 0.000168 \\
\hline$L Y M\left(\right.$ count $\left.\times 10^{9} \cdot l^{-1}\right)$ & $37.4 \pm 6.4$ & 0,4 & 0.006884 & 0.5 & 0.000936 \\
\hline FeNO50 (ppb) & $20.5 \pm 17.8$ & 0.01 & 0 & 0.01 & 0 \\
\hline$R n N O(p p b)$ & $392.9 \pm 155.3$ & & & & \\
\hline $\operatorname{LnNO}(p p b)$ & $402.1 \pm 169.7$ & & & & \\
\hline
\end{tabular}

BMI - body mass index, $\mathrm{w}$ - weight, $\mathrm{h}$ - height, $\mathrm{FEV}_{1}$ - forced expiratory volume in $1 \mathrm{~s}, \mathrm{FVC}$ - forced vital capacity, PEF - peak expiratory flow, WBC - white blood cells count, NEU - neutrophils, LYM - lymphocytes, MON - monocytes, EOS - eosinophils, BAS - basophils, I - liter, s - second, ppb - parts per billion, SD - standard deviation, r - Pearson correlation coefficient, $\mathrm{p}$ - significance. 


\section{Lung function tests}

Selected respiratory parameters were evaluated in whole study population, as well as on gender basis. Average FEV1/FVC ratio was $83.5 \pm 13.0 \%$ and PEF was $6.6 \pm 2.01 . \mathrm{s}^{-1}$, what represents normal values taking age, height and weight into account. Average FEV1/FVC values were higher in women $(86.3 \pm 13.9 \%)$ than in men $(80.9 \pm 10.8 \%)$; this difference was not statistically significant. On the contrary, average PEF values were significantly different in men $\left(7.9 \pm 2.11 . \mathrm{s}^{-1}\right)$ than in women $\left(5.9 \pm 1.71 . \mathrm{s}^{-1}\right)(\mathrm{p}<0.0001)($ Tables 1-3).

\section{Hematologic examination}

Average white blood cells count (WBC) in study population was $7.6 \pm 1.8 \times 10^{9} .1^{-1}$. Differences of average WBC values between men and women $\left(7.1 \pm 1.5 \times 10^{9} .1^{-1}\right.$ vs. $\left.7.0 \pm 1.9 \times 10^{9} .1^{-1}\right)$ were not significantly different. Average values of neutrophils, lymphocytes, monocytes, eosinophils and basophils are shown in Tables 1-3. Differences in WBC subtypes in men and women were not significant (Tables 1-3).

\section{Analysis of exhaled and nasal NO}

Average FeNO value in study population was $21.6 \pm 14.7 \mathrm{ppb}$. Difference in average values in women $(18.0 \pm 12.8 \mathrm{ppb})$ and men $(20.5 \pm 17.8 \mathrm{ppb})$ was not statistically significant. Nasal NO was evaluated for each nostril individually. Average $\mathrm{nNO}$ value in study population was $379.6 \pm 170.4 \mathrm{ppb}$ in right nostril and $401.6 \pm 207.8 \mathrm{ppb}$ in left nostril. Difference of average $\mathrm{nNO}$ values between left and right nostril was not statistically significant. Values of RnNO and LnNO were not significantly influenced by gender as well. Average values of RnNO and LnNO are shown in Tables 1-3.

\section{Pearson correlation coefficient}

Measured values of $\mathrm{nNO}(\mathrm{RnNO}$ and $\mathrm{LnNO}$ separately) were correlated with all parameters using Pearson correlation analysis.

Age: Moderate positive correlation was found for age and $\mathrm{nNO}$ values $(\mathrm{r}=0.3, \mathrm{p}=0.001204)$, this correlation with the same strength is present in women, but not in men - indicating lesser importance of age as a variable influencing $\mathrm{nNO}$ levels in healthy men.

Height: Analysis of entire group did not show correlation between $\mathrm{nNO}$ and height; however, height negatively correlated with $\mathrm{nNO}$ values in men $(\mathrm{r}=-0.4$, $\mathrm{p}<0.004523)$.

Weight: Weak negative correlation was found for $\mathrm{nNO}$ and body weight $(\mathrm{r}=-0.2, \mathrm{p}=0.024031)$ in entire group. This variable appears to be more important in women, where strong positive correlation between $\mathrm{nNO}$ and body weight was confirmed $(\mathrm{r}=0.6, \mathrm{p}<0.00001)$. In men there is no correlation between $\mathrm{nNO}$ and body weight.

$B M I$ : Results indicate moderate positive correlation of $\mathrm{nNO}$ and FeNO with BMI, $(\mathrm{r}=0.4$, $\mathrm{p}<0.00001$ for both parameters) for both, which confirms that nNO level increases with FeNO level and BMI value. Detailed analysis indicated the importance of BMI only in women subgroup $(\mathrm{r}=0.7, \mathrm{p}<0.00001)$.

$W B C$ : Weak negative correlation was found for $\mathrm{nNO}$ and absolute WBC count $(\mathrm{r}=-0.2, \mathrm{p}=0.014747)$. Counts of individual leukocyte subtypes correlated only weakly with nNO, weak correlation was found between $\mathrm{nNO}$ and neutrophils and lymphocytes for entire group, and this factors showed to have significance in men subgroup, (Table 1-3). This variable seems to have no effect on $\mathrm{nNO}$ values in women.

Lung function tests: No correlation between main parameters of lung function tests and $\mathrm{nNO}$ were found in our study.

$\mathrm{FeNO}$ : Results indicate strong correlation between $\mathrm{FeNO}$ and $\mathrm{nNO}$ in entire group $(\mathrm{r}=0.6$, $\mathrm{p}<0.00001$ ). Detailed calculation showed importance of this relationship in women subgroup. In women - FeNO, BMI, body weight and age have strong positive correlation with $\mathrm{nNO}$ values, while in men factors such height and WBC count play more important role (Table 1-3).

\section{Discussion}

While the measurement of FeNO is well-validated method routinely used in clinical settings for asthma diagnosis and control, measurement of nNO still needs standardization to become reliable tool for diagnosis and control of upper airway diseases (Scadding and Scadding, 2009).

This study was aimed to establish reference values for $\mathrm{nNO}$ measurement by $\mathrm{NIOX}$ MINO ${ }^{\circledR}$ device using tidal breathing and velum closure technique. Main findings of our study are the reference values of $\mathrm{nNO}$ for otherwise healthy adult population, which are $379.6 \pm 170.4 \mathrm{ppb}$ for $\mathrm{RnNO}$ and $401.6 \pm 207.8 \mathrm{ppb}$ for LnNO. In women, factors as FeNO, BMI, body weight and age have strong correlation with $\mathrm{nNO}$, while in men the factors as height and WBC count should be 
considered as variables modulating nNO levels.

A number of techniques have been employed to ensure sampling from the upper airways including breath holding, breathing against resistance or tidal breathing with velum closure. Such a variety of techniques considerably contributes to inconsistencies in reference values of $\mathrm{nNO}$ (Struben et al. 2005). We used tidal breathing method because majority of our subjects were not able to handle other techniques necessary for the air sampling. Nevertheless, our data are comparable to those obtained by measurements using breath holding techniques, which are used to avoid contamination of nasal samples by air exhaled from the lower airways (Kharitonov et al. 1997, Struben et al. 2005).

Reference values of nNO measured by other authors using the technique with breath holding are $450-900 \mathrm{ppb}$ (Scadding and Scadding 2009). It is impossible to compare these values with our data with absolute accuracy, because the measurements were carried out by different methods and different type of devices (Struben et al. 2005, Lee et al. 2012). Work of Geraldi et al. (2016) reports reference values of $\mathrm{nNO}$ 160-733 ppb. The later work used the same technique and the same device as our study. Our data match better with the study of Geraldi; however, these authors recruited only 32 subjects, what represents substantial limitation of their study. Our reference values nearly match with both Scadding's and Geraldi's work and according to our measurements, concentrations ranging from $155 \mathrm{ppb}$ to $932 \mathrm{ppb}$ are normal values for otherwise healthy subjects.

Moderate positive correlation was found for age and $\mathrm{nNO}$ values in entire group, this correlation with the same strength is present in women subgroup, but not in men, indicating lesser importance of age as a variable influencing $\mathrm{nNO}$ in men. Age seems to be important in children, but there is less of agreement across the studies regarding age in adults. The largest study to date identified the importance of age and height as factors affecting FeNO (Corbelli and Hammer 2005). Interestingly, FeNO increases with age and in population older than 65 years the gender differences were not observed, unlike what was observed in younger subjects (Malerba et al. 2016). Less data is available for nNO. It is hypothesized that $\mathrm{nNO}$ concentrations increase from birth until the age of 10 with pneumatisation of sinuses, but further work is necessary to clarify age-related changes in nNO output from infancy to adulthood using comparable methods (Corbelli and Hammer 2005). It was believed that $\mathrm{nNO}$ concentrations in adults are not affected by aging; however, our study showed the relationship between these variables, despite the age of our study population does not cover huge range (average age of subjects is 25 years).

Gender differences exist in respiratory physiology and our results indicate that nNO levels are modulated by different factors in women (age, weight, $\mathrm{BMI}$ ) and in men (height and count of WBC). Concerning the relationship of estrogen or testosterone and NO, gender should be one of the most important factors affecting the values of $\mathrm{nNO}$ and FeNO in clinical practice (Liu et al. 2015). Although it is generally accepted that gender differences exist in FeNO levels, there is still a debate about these results, because many studies, including ours, did not confirm differences in FeNO between genders (Alexanderson et al. 2012). Our study failed to show any gender-related differences in FeNO and in addition also in nNO values. This is in agreement with literature sources. Gender-related differences in $\mathrm{nNO}$ values have not been confirmed so far (Kharitonov et al. 1997, Taylor et al. 2007).

Values of $\mathrm{nNO}$ correlate positively with body weight and BMI in women subgroup. Uppalapati et al. (2016) found that obese individuals have significantly higher FeNO. This mutual interaction between FeNO, nNO and BMI may indicate relationship between obesity and airway inflammation diseases, mainly bronchial asthma; however, relationship between obesity, BMI and nNO has not been confirmed so far.

Multiple regression analysis published by Malmberg et al. (2006) demonstrated significant connection between FeNO and age, height, weight and body surface, and points out that height is the best independent variable for FeNO. Correlation of FeNO and nNO to height can be explained by the theory that increasing the total surface area of respiratory tract also increases the production of NO (Abba 2009, Liu et al. 2015), but correlation analysis for $\mathrm{nNO}$ and height has never been published. Our study found negative correlation between height and $\mathrm{nNO}$ in men, what is in conflict with data published for FeNO and expectation for nNO data. The negative correlation represents statistical relationship between data and does not necessarily represent biological relationship between two variables. The size and distribution of the data in the variable also should be taken into account. ATS \& ERS recommend calculating NO to body surface area rather to height, weight or BMI, because of many inconsistencies in these studies, majority of which share conflicting results (ATS 
and ERS 2005). The magnitude of the effect of the patient-related factors alone or in combination is potentially clinically significant rather than the factor itself.

It was already suggested that concentrations of FeNO can be influenced by lung functions tests manoeuvers performed shortly before FeNO detection. There are recent studies indicating that concentrations of FeNO are not significantly influenced and the pre-test and post-test concentrations are not significantly different (Karampitsakos et al. 2016). No data are available about the effect of manoeuvers of FVC on nNO concentrations; however, some studies report the effect of breath holding and nasal closure. High nNO levels detected during binasal sampling whilst mouth breathing were increased from over $390 \mathrm{ppb}$ up to $\geq 1,000 \mathrm{ppb}$ during breath-holding (Kharitonov et al. 1997), or up to 1,500-2,000 ppb after nasal cavities had been occluded for $120 \mathrm{~s}$ (Narang et al. 2002). Breath-holding and closure of the nose by nose clip are parts of lung function tests and this should also be taken into account, especially if sequential tests are performed, e.g. spirometry followed by $\mathrm{nNO}$ measurement. Based on these results, we strongly recommend to avoid such a sequence and to detect NO values as first in the sequence. To avoid such influences in our study completely, measurements of FeNO and nNO were performed on separate days. Our study did not find any correlation between lung function tests and $\mathrm{nNO}$ values in healthy volunteers and no data about the relationship between these variables are available.

There are two methods of nasal air sampling, binasal (suction of air from both nostrils) and measurement from single nostril. The later method may lead to either false-positive or false-negative results mainly due to extremely high inter-individual variability of nNO values (Silkoff et al. 1999, Struben et al. 2005). In our study, $\mathrm{nNO}$ values were measured for right and left nostril separately, because each nostril operates independently, what results to different air flow rates, thermoregulation processes, hydration etc. (Warren et al. 2010). nNO values can be influenced also by anatomical factors and by nasal cycle (White et al. 2015). Our study measured reference values of $\mathrm{nNO}$ concentrations for right and left nostril, and there were no statistically significant differences between them. Since there is a lack of relevant information describing the effect of nasal cycle on $\mathrm{nNO}$ values, we recommend measurement in both the right and left nostril and then calculation of an average value for clinical measurement. If any considerable difference occurs, it should be clarified by ENT examination.

Correlation analysis indicates that relationship between $\mathrm{nNO}$ values and WBC count exists in men subgroup. Literature documents substantial relationship between eosinophils, eosinophilic inflammation and $\mathrm{nNO}$ values, typically seen in allergies (Lee et al. 2012, Uhliarova et al. 2015). Relationship between neutrophils and nNO signaling pathways is less studied, e.g. studies show that NO modulates LTB4-induced neutrophil recruitment and subsequent fluid secretion in the nose (Cardell et al. 2000). Relationship between neutrophils and nNO is important in sinuses. The main defense strategy against infection in sinuses seems to depend more on high concentrations of NO than on phagocytic cells. High concentrations of NO inhibit neutrophil chemotaxis and proliferative responses. This contrasts with processes in other cavities such as alveolar or peritoneal cavities, where phagocytic cells constitute the main defense and NO concentrations are low (Serrano et al. 2004). A negative correlation for both the WBC and for neutrophils was identified in our male volunteers, which is in agreement with previously cited work and may explain reciprocal relationship between $\mathrm{nNO}$ and neutrophils. This relationship may indicate the importance of interaction of neutrophils with endothelial cells in the nose and sinuses (Cardell et al. 2000, Bogdan 2011). Even though there are multiple relationships between WBC population and NO signaling pathways, WBC count in blood should be taken into consideration as a factor potentially influencing nNO levels. Further research is necessary to understand this interaction.

There are some limitations of our study. As it was already suggested, our subjects are quite young (the average age is 25 years) and this sample does not match with range of adult subjects (18-65 years), which would very likely provide more optimal reference values. 25 and 45 years old women differ considerably e.g. in average percentage of body fat, BMI and also hormonal status (Launer and Harris 1996). The population was quite homogenous and we do believe that recruitment of volunteers in fourth, fifth and sixth decade would provide more reliable data.

Another limitation is absence of follow-up measurements to observe reproducibility of $\mathrm{nNO}$ data, especially if nNO values are highly variable and under influence of many physiological processes. Knowing there are more questions than answers in the $\mathrm{nNO}$ 
measurement field, we hope that our study brought original data and will motivate further research.

\section{Conclusions}

In this study, we obtained reference values of nNO in 141 healthy volunteers and based on correlation analysis, the most important factors potentially influencing nNO levels were identified. It seems that measurement of nNO has a similar potential to FeNO, but there are still many factors which should be clarified prior to standardization of this test and its application to clinical practice.

\section{Conflict of Interest}

There is no conflict of interest.

\section{Acknowledgements}

This work was supported with Centre of Experimental and Clinical Respirology, ITMS code of Project 26220120004, which is co-financed from EU sources (ERDF), VEGA 1/0305/14 and APVV-15-0075.

\section{References}

ABBA AA: Exhaled nitric oxide in diagnosis and management of respiratory diseases. Ann Thorac Med 4: 173-181, 2009.

ALEXANDERSON C, OLIN AC, DAHLMAN-HÖGLUND A, FINIZIA C, TORÉN K: Nasal nitric oxide in a random sample of adults and its relationship to sensitization, cat allergen, rhinitis, and ambient nitric oxide. $A m$ J Rhinol Allergy 26: e99-e103, 2012.

ALVING K, WEITZBERG E, LUNDBERG JM: Increased amount of nitric oxide in exhaled air of asthmatics. Eur Respir J 6: 1368-1370, 1993.

ANTOSOVA M, STRAPKOVA A, MIKOLKA P, MOKRY J, MEDVEDOVA I, MOKRA D: The influence of L-NAME on iNOS expression and markers of oxidative stress in allergen-induced airway hyperreactivity. $A d v$ Exp Med Biol 838: 1-10, 2015.

ATS/ERS Recommendations for standardized procedures for the online and offline measurement of exhaled lower respiratory nitric oxide and nasal nitric oxide, 2005. Am J Respir Crit Care Med 171: 912-930, 2005.

BALBI B, PIGNATTIP, CORRADI M, BAIARDI P, BIANCHI L, BRUNETTI G, RADAELI A, MOSCATO G, MUTTI A, SPANEVELLO A, MALERBA M: Bronchoalveolar lavage, sputum and exhaled clinically relevant inflammatory markers: values in healthy adults. Eur Respir J 30: 769-781, 2007.

BANOVCIN P, JESENAK M, MICHNOVA Z, BABUSIKOVA E, NOSAL S, MIKLER J, FABRY J, BARRETO M: Factors attributable to the level of exhaled nitric oxide in asthmatic children. Eur J Med Res 14 (Suppl 4): 9-13, 2009.

BOGDAN C: Regulation of lymphocytes by nitric oxide. Methods Mol Biol 677: 375-393, 2011.

CARDELL LO, AGUSTÍ C, NADEL JA: Nitric oxide-dependent neutrophil recruitment: role in nasal secretion. Clin Exp Allergy 30: 1799-1803, 2000.

CORBELLI R, HAMMER J: Measurement of nasal nitric oxide. Prog Respir Res 33: 181-189, 2005.

EVANS JD: Straightforward Statistics for the Behavioral Sciences. Brooks/Cole Publishing, Pacific Grove, 1996,600 p.

GELARDI M, ABBATTISTA G, QUARANTA VN, QUARANTA N, SECCIA V, BUTTAFAVA S, FRATI F, CIPRANDI G: Standardization procedure for the nasal nitric oxide measurement method using Niox MINO ${ }^{\circledR}$ and the tidal-breathing technique with velum-closure. J Biol Regul Homeost Agents 30: 853-858, 2016.

GUSTAFSSON LE, LEONE AM, PERSSON MG, WIKLUND NP, MONCADA S: Endogenous nitric oxide is present in the exhaled air of rabbits, guinea pigs and humans. Biochem Biophys Res Commun 181: 852-857, 1991.

JATAKANON A, LIM S, KHARITONOV SA, CHUNG KF, BARNES PJ: Correlation between exhaled nitric oxide, sputum eosinophils, and methacholine responsiveness in patients with mild asthma. Thorax 53: 91-95, 1998.

JORISSEN M, LEFEVERE L, WILLEMS T: Nasal nitric oxide. Allergy 56: 1026-1033, 2001.

KARAMPITSAKOS T, PROTOPAPAS A, GIANOLOUDI M, CHATZIMICHAIL A, PARASKAKIS E: The effect of bronchodilation and spirometry on exhaled nitric oxide. Eur Respir J 48 (Suppl 60): PA3356, 2016.

KHARITONOV S, ALVING K, BARNES PJ: Exhaled and nasal nitric oxide measurements: recommendations. Eur Respir J 10: 1683-1693, 1997. 
KHARITONOV SA, RAJAKULASINGAM K, O'CONNOR B, DURHAM SR, BARNES PJ: Nasal nitric oxide is increased in patients with asthma and allergic rhinitis and may be modulated by nasal glucocorticoids. J Allergy Clin Immunol 99: 58-64, 1997.

KOPINCOVA J, PUZSEROVA A, BERNATOVA I: Chronic low-dose L-NAME treatment effect on cardiovascular system of borderline hypertensive rats: feedback regulation? Neuro Endocrinol Lett 29: 784-789, 2008.

LAUNER LJ, HARRIS T: Weight height and body mass index distributions in geographically and ethnically diverse samples of older persons. Age Ageing 25: 300-306, 1996.

LEE KJ, CHO SH, LEE SH, TAE K, YOON HJ, KIM SH, JEONG JH: Nasal and exhaled nitric oxide in allergic rhinitis. Clin Exp Otorhinolaryngol 5: 228-233, 2012.

LEIGH MW, HAZUCHA MJ, CHAWLA KK, BAKER BR, SHAPIRO AJ, BROWN DE, LAVANGE LM, HORTON BJ, QAQISH B, THE GENETIC DISORDERS OF MUCOCILIARY CLEARANCE CONSORTIUM: Standardizing nasal nitric oxide measurement as a test for primary ciliary dyskinesia. Ann Am Thorac Soc 10: 574-581, 2013.

LIU D, HUANG Z, HUANG Y: Clinical analysis of fractional exhaled and nasal nitric oxide in allergic rhinitis children. J Allergy Ther 6: 204, 2015.

MALERBA M, DAMIANI G, CARPAGNANO GE, OLIVINI A, RADAELI A, RAGNOLI B, FOSCHINO MP, OLIVIERI M: Values in elderly people for exhaled nitric oxide study. Rejuvenation Res 19: 233-238, 2016.

MALMBERG LP, PETÄYS T, HAAHTELA T, LAATIKAINEN T, JOUSILAHTI P, VARTIAINEN E, MÄKELÄ MJ: Exhaled nitric oxide in healthy nonatopic school-age children: determinants and height-adjusted reference values. Pediatr Pulmonol 41: 635-642, 2006.

NARANG I, ERSU R, WILSON NM, BUSH A: Nitric oxide in chronic airway inflammation in children: Diagnostic use and pathophysiological significance. Thorax 57: 586-589, 2002.

SCADDING G, SCADDING GK: Update on the use of nitric oxide as a noninvasive measure of airways inflammation. Rhinology 47: 115-120, 2009.

SERRANO C, VALERO A, PICADO C: Nasal nitric oxide. Arch Bronconeumol 40: 222-230, 2004.

SILKOFF PE, C HATKIN J, QIAN W, CHAKRAVORTY S, GUTIERREZ C, FURLLOT H, MCCLEAN P, RAI S, ZAMEL N, HAIGHT J: Nasal nitric oxide: a comparison of measurement techniques. Am $J$ Rhinol 13: 169-178, 1999.

STRUBEN VM, WIERINGA MH, FEENSTRA L, DE JONGSTE JC: Nasal nitric oxide and nasal allergy. Allergy 61: 665-670, 2006.

STRUBEN VM, WIERINGA MH, MANTINGH CJ, BRUINSMA SM, DE JONGSTE JC, FEENSTRA L: Silent and humming nasal NO measurements in adult aged 18-70 years. Eur J Clin Invest 35: 653-657, 2005.

TAYLOR DR, MANDHANE P, GREENE JM, HANCOX RJ, FILSELL S, MCLACHLAN CHR, WILLIAMSON AJ, COWAN JO, SMITH AD, SEARS MR: Factors affecting exhaled nitric oxide measurements: the effect of sex. Respir Res 8: 82, 2007.

UHLIAROVA B, KOPINCOVA J, KOLOMAZNIK M, ADAMKOV M, SVEC M, CALKOVSKA A: Comorbidity has no impact on eosinophil inflammation in the upper airways or on severity of the sinonasal disease in patients with nasal polyps. Clin Otolaryngol 40: 429-436, 2015.

UPPALAPATI A, GOGINENI S, ESPIRITU JR: Association between Body Mass Index (BMI) and fraction of exhaled nitric oxide (FeNO) levels in the National Health and Nutrition Examination Survey (NHANES) 2007-2010. Obes Res Clin Pract 10: 652-658, 2016.

WARREN NJ, CRAMPIN EJ, TAWHAI MH: The role of airway epithelium in replenishment of evaporated airway surface liquid from the human conducting airways. Ann Biomed Eng 38: 3535-3549, 2010.

WHITE DE, BARTLEY J, NATES RJ: Model demonstrates functional purpose of the nasal cycle. Biomed Eng Online 14: 38, 2015. 